\title{
A Comparative Study of Lipid Profile and Atherogenic Index of Plasma Among the Pre and Post-Menopausal Women
}

\author{
*S Khanduker ${ }^{1}$, R Ahmed ${ }^{2}$, M Nazneen ${ }^{3}$, A Alam ${ }^{4}$, F Khondokar $^{5}$
}

\begin{abstract}
Background: Menopausal health in our environment has received little attention. As a independent risk factor for dyslipidemia, the degree and pattern of derangement, though difficult to assess may adversely affect the cardiovascular health of our women.
\end{abstract}

Objectives: To estimate the serum lipid profile and the atherogenic index of plasma among the pre and post- menopausal women.

Materials and Methods: After an overnight fasting blood samples were collected from a group of 339 women, 140 premenopausal aged between 25-50 years and 199 postmenopausal aged between 51-70 years. Serum total cholesterol (TC), triglycerides (TG) and HDL-cholesterol were estimated by enzymatic methods and LDL-cholesterol by established mathematical methods. Atherogenic index of plasma (AIP) were calculated by using the formula $(\log$ TG/HDL-C). Statistical analysis was carried out in the two groups using the unpaired $t$ test. Results were expressed as mean \pm SD. P values $<0.05$ were considered to be statistically significant.

Results: There were statistically significant increase in serum TC $(191.21 \pm 45.50 \mathrm{mg} / \mathrm{dl})$, TG $(185.83 \pm$ $111.83 \mathrm{mg} / \mathrm{dl})$ and LDL-C $(118.71 \pm 38.48 \mathrm{mg} / \mathrm{dl})$ in post-menopausal women. Their HDL-C level $(38.67 \pm 10.00 \mathrm{mg} / \mathrm{dl})$ was significantly decreased. The calculated atherogenic index of plasma (AIP) was significantly higher $(0.63 \pm 0.27)$ in post-menopausal women as compared to that in premenopausal women $(0.50 \pm 0.29)$.

Conclusion: Menopause leads to changes in lipid profile. By elevating LDL and the reduction of cardioprotective HDL is an indication that menopause is an independent risk factor for developing cardiovascular disease. These changes are caused by loss of cardio-protective effect of oestrogen.

Key Words: CAD: Coronary Artery Disease, CVD: Cardiovascular Disease, LH: Leutinizing Hormone, FSH: Follicle Stimulating Hormone, AIP: Atherogenic Index of Plasma

\section{Introduction}

Menopause is defined as cessation of menstruation for a period longer than one year, and begins with changes in ovarian function. ${ }^{1}$ The median age for the final menstrual period is about 51 years, when the ovarian follicular reserve and indeed oestrogen production is significantly reduced.2,3 A woman from her intrauterine life till the end experiences

different stages of reproductive life under the influence of female hormones, which is a physiological process. ${ }^{4}$ The sex hormones which are secreted in minute quantities not only play an important role in woman,s reproductive life but also influence metabolism in a significant way. Specially Estrogen plays important role in lipid metabolism.

1Dr. Sadia Khanduker, Assistant Professor, Department of Biochemistry, Bangladesh Medical College, Dhanmondi, Dhaka 2Dr. Rumana Ahmed, Assistant Professor, Department of Biochemistry, CARe Medical college, Iqbal road Dhaka ${ }^{3}$ Dr. Mafruha Nazneen, Professor, Department of Biochemistry, Dhaka Central International Medical College ${ }^{4}$ Dr. Anawarul Alam, Associate Professor, Department of Biochemistry, Dhaka Central International Medical College 5Dr. Farhana Khondokar, Assistant Professor, Department of Biochemistry, Anwer Khan Modern Medical College *Corresponding author

Date of submission: 09.09.2017, Date of acceptance: 11.11.2017 
They affect mainly serum cholesterol and lipoproteins and hence has an indirect role in coronary heart disease (CAD) ${ }^{5}$

During the menopausal transition, more erratic fluctuations in female reproductive hormones are seen. ${ }^{6}$ The hormonal changes associated with menopause are low plasma levels of estrogen and marked increase in leutinizing hormone (LH) 3 to 5 fold and follicle stimulating hormones (FSH) 10-20 folds. ${ }^{7}$ Reports indicate that while a women may stop menstruating endogenous cycling and ovulation may still occur for months or even years. ${ }^{8}$ High levels of gonadotropines are maintained during 2 or 3 years after menopause. In later age, levels of gonadotropins decrease again or remain only mildly elevated. LH stimulates ovaries to produce androgens, which persists until advanced years, so that ovary preserves its function of an endocrine organ1. Decreased oestrogen during and after menopause causes structural, physiological and biochemical changes that alter the general health status of a women. Lack of the protection of estrogen influences the risk of cardiovascular diseases (CVD), such as ageing, increased obesity or android pattern of body fat distribution, decreasing resting metabolic rate and physical activity. ${ }^{9}$

Lipid profile consists of a group of biochemical tests often used in predicting diagnosing and treating lipid-related disorders including atherosclerosis. ${ }^{10,11}$ Increased levels of cholesterol, triglycerides, LDL, apolipoprotein B and decreased levels of HDL and apolipoprotein A are characteristics of lipid profile in menopause. ${ }^{12}$ During menopause, concentration of triglyceride also increases, which is related to the increase of the abdominal fat count and insulin resistance. Menopause causes decrease of HDL concentration and changes in HDL structure which is inversely proportional with the abdominal fat level. ${ }^{13}$

This group of women is also at higher risk of $\mathrm{CVD}^{14}$, but it is yet unclear wheather increase in risk is caused by increased androgen level or decreased estrogen level. ${ }^{15} \mathrm{Up}$ to 50 years prevalence of CAD is lower in woman than man but due to the hormonal changes it increases after menopause. ${ }^{16}$ Atherogenic index of plasma (AIP) calculated as $\log$ (TG/HDL-C) has been used to assess the cardiovascular risk. People with high AIP have a higher risk for coronary heart disease (CHD) than those with low AIP. Triglyceride (TG) and high density lipoprotein-cholesterol (HDL-C) in AIP reflect the balance between the atherogenic and antiatherogenic lipoproteins respectively. Triglyceride (TG) and HDL cholesterol in AIP reflect the balance between the atherogenic and protective lipoproteins. The index correlates with the size of pro- and antiatherogenic lipoprotein particle. AIP was done to detect the risk of CVD. By some practitioners as a significant predictor of atherosclerosis in the assessment of cardiovascular risk factors this formula has been successfully used as an additional index. It has been suggested that AIP values of- 0.3 to 0.1 are associated with low, $>0.1$ to 0.24 with medium and above 0.24 with high CVD risk. ${ }^{17,18}$

\section{Materials and Methods}

This cross sectional study was carried out in Bangladesh medical college hospital dhanmondi, Dhaka from the period of April to July 2017. The outdoor patients coming to the hospital who fulfilled the criteria were included in this study. Study group included 339 subjects, among them 140 were premenopausal aged between 25-50 years and 199 were postmenopausal aged between 51-70 years. The postmenopausal women who were studied were those with a history of natural menopause, who had cessation of menstruation for a minimum of one year and premenopausal women who were studied were those who had regular menstruation.

After taking consent, venous blood samples were collected from all the subjects after 12 hours overnight fast. Then the serum was extracted and analyzed immediately for lipid profile study. Serum lipid profile including total cholesterol, triglyceride and HDL cholesterol were estimated by enzymatic methods analyzed in the clinical pathology lab by Hitachi Cobas Model: C-311 biochemistry Autoanalyzer machine. Serum LDL was calculated by using Friedewald's formula. ${ }^{19}$ Atherogenic index of plasma (AIP) were calculated by using the mathematical formula (log TG/HDL-C). ${ }^{17,18}$

The results obtained were statistically analyzed and compared between the two groups of the study. Baseline characteristics of the study participants were expressed in mean \pm standard deviation. 
Comparison of mean was done by unpaired t test. The statistical analysis was performed using SPSS 22.0 version computer software for windows. Statistical significance was considered at $\mathrm{P}<0.05$.

\section{Exclusion}

Subjects with cardiovascular disease, hypertension, diabetes mellitus, hepatic, metabolic and renal disease, and those who were on exogenous hormones or on hormone replacement therapy or taking lipid lowering drugs were excluded from the study.

\section{Results}

Significant increase in Total Cholesterol, Triglyceride and LDL cholesterol and decrease in HDL were observed in women with menopausal transition period compared to women in young age group. This is showed in Table no. 1 and Figure 1.

Table-I: Comparison of the components of lipid profile among the pre and post-menopausal women $(n=339)$

\begin{tabular}{lcccc}
\hline & $\begin{array}{c}\text { TC }(\mathrm{mg} / \mathrm{dl}) \\
{[\mathrm{Mean} \pm \text { SD] }}\end{array}$ & $\begin{array}{c}\text { HDL }(\mathrm{mg} / \mathbf{d l}) \\
{[\mathrm{Mean} \pm \mathrm{SD}]}\end{array}$ & $\begin{array}{c}\text { LDL }(\mathrm{mg} / \mathrm{dl}) \\
{[\mathrm{Mean} \pm \mathrm{SD}]}\end{array}$ & $\begin{array}{c}\text { TG }(\mathrm{mg} / \mathrm{dl}) \\
{[\mathrm{Mean} \pm \mathrm{SD}]}\end{array}$ \\
\hline $\begin{array}{l}\text { Pre menopausal } \\
(\mathrm{n}=140)\end{array}$ & $182.02 \pm 33.45$ & $41.33 \pm 10.96$ & $110.92 \pm 30.80$ & $149.48 \pm 101.29$ \\
$\begin{array}{l}\text { Post menopausal } \\
(\mathrm{n}=199)\end{array}$ & $191.21 \pm 45.50$ & $38.67 \pm 10.00$ & $118.71 \pm 38.48$ & $185.83 \pm 111.83$ \\
$\begin{array}{l}\text { P value } \\
\text { Significance }\end{array}$ & 0.043 & 0.021 & 0.048 & 0.002 \\
\hline
\end{tabular}

Unpaired t test was done to measure the level of significance

$N S=$ Not significant

$S=$ Significant

Table 1 shows mean, standard deviation and $\mathrm{p}$ value for TC, TG, LDL and HDL in both groups of women

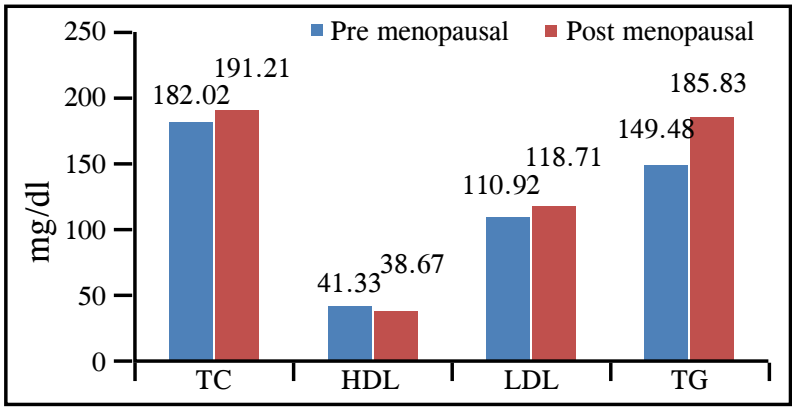

Fig.-1: Bar diagram showing comparison of the components of lipid profile (Total cholesterol TC, HDL, LDL and triglyceride TG) in pre and post menopausal women.
Table-II: AIP (Atherogenic index of plasma) among the premenopausal and post menopausal women $(n=339)$

\begin{tabular}{lccc}
\hline & $\begin{array}{c}\text { HDL }(\mathrm{mg} / \mathrm{dl}) \\
{[\mathrm{Mean} \pm \text { SD] }}\end{array}$ & $\begin{array}{c}\text { TG }(\mathbf{m g} / \mathbf{d l}) \\
{[\mathrm{Mean} \pm \text { SD }]}\end{array}$ & $\begin{array}{c}\text { AIP } \\
\text { Log(TG/HDL) } \\
{[\text { Mean } \pm \text { SD }]}\end{array}$ \\
\hline $\begin{array}{l}\text { Pre menopausal } \\
(\mathrm{n}=140)\end{array}$ & $41.33 \pm 10.96$ & $149.48 \pm 101.29$ & $0.50 \pm 0.29$ \\
$\begin{array}{l}\text { Post menopausal } \\
(\mathrm{n}=199)\end{array}$ & $38.67 \pm 10.00$ & $185.83 \pm 111.83$ & $0.63 \pm 0.27$ \\
$\begin{array}{l}\text { P value } \\
\text { Significance }\end{array}$ & 0.021 & 0.002 & $<0.001$ \\
& $\mathrm{~S}$ & $\mathrm{~S}$ & $\mathrm{~S}$ \\
\hline
\end{tabular}

Unpaired t test was done to measure the level of significance. $N S=$ Not significant

$S=$ Significant

\section{Discussion}

In the postmenopausal period, there are reduced levels of estrogen which lead to derangement of lipid and lipoprotein profiles. ${ }^{20}$ Estrogens have various cardioprotective mechanisms and it is lost with the onset of menopause. ${ }^{21}$

Post menopausal women in our study had higher TC, TG, LDL-C, atherogenic index and a lower HDL-C. These finding may predisposes them to high risk of incidence of CVD. This agrees with the findings of Nwagha et $\mathrm{al}^{11}$, Woodard et $\mathrm{al}^{22}$ Srinivas ${ }^{23}$, Bade et $\mathrm{al}^{24}$, Dowling. ${ }^{25}$ A similar observation was also made by Carr et al. ${ }^{12}$, Berg et al. ${ }^{26}$, Mathews et $\mathrm{al}^{27}$, Berestein et $\mathrm{al}^{28}$, in postmenopausal caucasian women.

Serum TC was increased significantly may be due to the estrogen deficiency thus providing lipid profile highly favorable to atherogenic potential. $9,29,30,31$

In our study when compared with the two groups of women post menopausal women were found with high TG and were statistically significant $(\mathrm{p}<0.05)$. These findings are in accordance with other studies done by Hallberg and Svanberg ${ }^{32}$ and Welty. ${ }^{33}$ In the postmenopausal women there is increased fat accumulation and increased release of FFA into circulation and excess FFA provide substrate for hepatic TG synthesis.

In our study postmenopausal women had high levels of LDL when compared to premenopausal women and was statistically significant $(<0.05)$. These findings are in accordance with other studies of Kalavathi $^{30}$, Kwiterovich ${ }^{34}$ and Swapnali. ${ }^{35}$ 
Lipoprotein lipase (LPL) catalyzes the hydrolysis of VLDL to form intermediate density lipoprotein and later LDL. Estrogen deficiency after menopause increases the plasma LPL and hepatic TG lipase activity causing plasma LDL to accumulate and also leads to down regulation of LDL receptors. ${ }^{31,35,36}$

In the present study, there were statistically significant increases in TC, TG, LDL and AIP when post menopausal women compared to the premenopausal counterparts. These findings are similar to reports from other part of this world done by Dowling ${ }^{25}$, Nwagha ${ }^{37}$ and Stephenson. ${ }^{38}$

Studies also showed that menopause is associated with low HDL level. ${ }^{29,39}$ There have been suggestions that isolated low HDL levels themselves may be major risk factors for coronary heart disease (CHD) in post menopausal women. ${ }^{40,41}$ Furthermore it has also been estimated that for any $1.0 \mathrm{mg} / \mathrm{dl}$ or $0.026 \mathrm{mmol} / \mathrm{ml}$ increase in HDL there is a $3 \%$ decrease in risk of coronary artery disease and a $4.7 \%$ decrease in the risk of mortality from cardiovascular disease. ${ }^{42}$

The findings in this study contradict the findings of Igweh et $\mathrm{al}^{21}$ who demonstrated no significant difference in TC, TG and VLDL-C between pre and post menopausal women. The findings of Osakue ${ }^{42}$ who demonstrated higher levels of HDL-C and TC only among postmenopausal women also contradict these findings.

The Atherogenic index of plasma which is a mathematical relationship between TG and HDL has been successfully used as an additional index when assessing cardiovascular risk factors. ${ }^{17,18}$ Indeed, It has been demonstrated that the development of CAD is a function of the particle size of LDL and HDL with the small particle size exhibiting great atherogenic potential. ${ }^{44}$ Indeed cholesterol esterification rate in HDL-C plasma (FERHDL) has a strong relationship between lipoprotein particle sizes and thus can be considered as a functional risk marker for CAD. ${ }^{17,45}$ More recently, researchers have shown that the log arithmetically transformed ratio TG/HDL is the best determinant for FERHDL and thus a better predictor of cardiovascular risk than other previously used lipid parameters. ${ }^{46}$ Furthermore, in situations where other atherogenic risk parameters appear normal AIP may be the diagnostic alternative.
Dislipidemia in our postmenopausal women is indicative of their susceptibility to atherosclerosis and other cardiovascular disorders. The relationship between the concentrations of lipids and their associated blood transporting lipoproteins with the development of cardiovascular disease has been proven.

Identified postmenopausal women with dyslipidemia should be followed up for years to detect development of atherosclerosis. This will go a long way in improving the healthcare of postmenopausal women in our country and even globally.

\section{Conclusion}

Menopause leads to changes in lipid profile by elevating TC, TG, LDL and decreasing HDL, thus increasing the risk of cardiovascular disease. Due to the loss of cardioprotective effect of estrogen there is change in the lipid pattern. There are so many studies showing the beneficial effects of hormone replacement therapy on the lipid profile in post-menopausal women. Atherogenic index which can easily be calculated from standard lipid profile can act as an adjunct that significantly add predictive value beyond that of the individual lipids. Dietary interventions and increased physical activity should also be encouraged in post menopausal women, especially when there are other associated risk factors.

Conflict of interest: None

\section{References}

1. Mesalic L, Tupkovic E, Kendic S, et al. Correlation between hormonal and lipid status in women in menopause. Bosnian journal of basic medical sciences 2008; 8(2): 189-192.

2. Kilim SR and Chandala SR. A comparative study of lipid profile and oestradiol in Pre and Post menopausal Women. Journal of Clinical and Diagnostic Research 2013; 7(B): 1596-1598.

3. Wolfman W. Reality check on menopause.Your Health report spring 2002; 40: 34-36.

4. Bhagya V, Hemalatha NR, Veeranna HB, et al. Serum lipid profile in Prepubertal, reproductive and post-menopausal women. Int $\mathrm{J}$ Biol Med Res 2011; 2(3): 639-642.

5. Deepti Gi, Shetty S, Rao AV, et al. Age related difference in the lipid profile in normal healthy women. NUJHS 2014; 4(2): 94-97. 
6. Jain A, Santoro N. Endocrine mechanisms and management for abnormal bleeding due to perimenopausal changes. Clin Obstet Gynecol 2005; 48: 29.

7. Usoro CAO, Adikwuru CC, Usoro IN et al. Lipid profile of Post-menopausal women in Calabar, Nigeria. Pakistan Journal of Nutrition 2006; 5(1): 79-82.

8. Wald M. Menopause: A natural transition. Advanced Medicine 2003; 12: 25-29.

9. Madhavi D, Kulkarni, Kammar KF. Lipid profile in postmenopausal women in hubli city. J Pub Health Med Res 2014; 2(1): 25-28.

10. Brites FD, Bonavita CD, Cloes M,et al VLDL compositional changes and plasma levels of triglycerides and high density lipoproteins. Clinica Cheimica Acta 1998; 269: 107-124.

11. Nwagha UI, Ikekpeazu EJ, Ejezie FE, et al. Atherogenic index of plasma as useful predictor of cardiovascular risk among postmenopausal women in Enugu, Nigeria.African Health Sciences 2010; 10(3): 248-252.

12. Carr MC, Kim KH, Zambon A, et al. Changes in LDL density across the menopausal transition. J Invest Med 2000; 48: 245-250.

13. Lamarche B, Moorjani S, Cantin B, et al. Association of HDL2 and HDL 3 subfractions with ischemic heart disease in men. Prospective results from the Quebec cardiovascular study. Arterioscler Thromb Vasc Biol 1997; 17: 1098-1105.

14. Gower BA, Naggy TR, Goran MI, et al. Fat distribution and plasma lipid-lipoprotein concentration in pre and postmenopausal women. Int J Obes. Relat Metab Disord 1998; 22(7): 605-611.

15. Van Beek AP, Derujiter-Heistek FC, Jansen H, et al. Sex steroids and plasmalipoprotein levels in healthy women: importance of androgens in the estrogen-deficient state. Metabolism 2004; 53(2): 187-192.

16. Kanwar G, Kirad S, Chawla L et al. A comparative study of serum lipid profile between premenopausal and post menopausal women in Kota, Rajasthan, India. IJRANSS 2014; 2(8): 61-66.
17. Dobiasova $\mathrm{M}$ and Frohlich $\mathrm{J}$. the plasma parameter $\log (\mathrm{TG} / \mathrm{HDL}-\mathrm{C})$ as an atherogenic index; correlation with lipoprotein particle size and esterification rate in apoB lipoprotein depleted plasma(FERHDL) .Clin Biochem 2001; 34: 583-588.

18. Tan MH, Johns D and Glazer N. Pioglitazone reduces atherogenic index of plasma in patients with type 2 diabetes. Clin chem 2004; 50:11841188.

19. Friedwald WT, Levy RI, Fredrickson D. Estimation of the concentration of low density lipoprotein cholesterol in plasma, without use of the preparative ultracentrifuge. Clin Chem 1972; 18: 499-502.

20. Bales AC. Insearch of lipid balance in older women; New studies raise questions about what works best. Postgraduate medicine 2000; 108(7): 57-72.

21. Igweh JC, Nwagha IU, Okaru JM. The effects of Menopause on the serum lipid profile of normal females of south East Nigeria. Nigerian Journal of physiological sciences 2005; 20(1-2): 48-53.

22. Woodard GA, Brooks MM, Baninas-Mitchell E, et al. Lipid, menopause and early atherosclerosis in study of women health across the nation. North American Menopause Soceity 2010; 18(4): 376-384.

23. Srinivas RK and Srinivas RC. A comparative study of lipid profile and oestradiol in pre and post menopausal women: Journal of clinical and diagnostic research 2013; 7(8): 1596-1598.

24. Bade G, Sheh S, Nahar P, et al. Effects of Menopause on lipid profile in relation to body mass index. Chronicles of young Scientists 2004; 5:20-24.

25. Dowling EA. How exercise affect lipid profile in women. The physician and sports medicine 2001; 29(9): 45-47.

26. Berg GV , MeschBoerol L, Sayegh FM, et al. Lipid and lipoprotein profile in menopausal transition, effects of hormones, age and fat distribution .Horm Metab Res 2004; 36(4): 215-220. 
27. Mathews KA, Wing RR, Kuller LH, et al. Influence of the perimenopause on cardiovascular risk factors and symptoms of middle aged healthy women. Arch Int Med 1994; 154: 2349-2355.

28. Berestein FG, Bengtson $\mathrm{C}$ and Herbert PN. Differences in LDL subfractions and apolipoproteins in premenopausal and postmenopausal women. J Clin Endocrinol Metab 1993; 40: 17-30.

29. Mathews KA, Meilahn E, Kuller LH et al. Menopause and risk factors for coronary heart disease. New Engl J Med 1989; 321: 641-646.

30. Kalavathi L, Dhruvanarayan HR, Zachariah E. Plasma estradiol and lipid profile in perimenopausal women. Indian J Physiol Pharmacol 1990; 35: 260-262.

31. Muzzio ML, Berg G, Zago V, et al .Circulating small dense LDL, endothelial injuring factors and fibronectin in healthy postmenopausal women.Clin Chim Acta 2007; 381: 157-163.

32. Hallberg L and Svanborg A. Cholesterol, phospholipids and triglycerides in plasma in $\mathbf{5 0}$ year old women. Influence of menopause, bodyweight, skinfold thickness, weight gain and diet in a random population sample. Acta Med Scand 1967; 181: 185-194.

33. Welty FK. Cardiovascular disease and dyslipidemia in women. Arch Intern Med 2001; 161: 514-522.

34. Kwiterovich PO, Coresh J, Smith HH, et al. Comparison of the plasma levels of apolipoproteins $\mathrm{b}$ and A-I and other risk factors in men and women with premature coronary artery disease. Am J Cardiol 1992; 69: 10151021.

35. Swapnali RK, Kisan R, Jayaprakash Murthy DS. Effect of menopause on lipid profile and apolipoproteins. Al-Ameen j Med Sci 2011; 4: 221-228.

36. Wakatsuki A, Sagara Y. Lipoprotein metabolism in postmenopausal and oophorectomized women. Obstet Gynecol 1995; 85: 523-528.
37. Nwagha UI, Igweh JC. Atherogenic index of plasma; a significant indicator for the onset of atherosclerosis during menopause in hypertensive females of south East Nigeria. Journal of college of medicine 2005 ; 10(2): 67-71.

38. Stephenson JC, Crook D, Godsland N. Influence of age and menopause on lipids and lipoproteins in healthy women: Atherosclerosis 1993; 98: 83-90.

39. Jensen J, Nilas L, Christiansen C. Influence of menopause on serum lipids and lipoproteins. Maturitas 1990; 12: 321-331.

40. Stensvold I, Urdal P, Thurmer $\mathrm{H}$ et al. High density lipoprotein cholesterol and coronary cardiovascular and all cause mortality among middle-aged Norwegian men and women. Eur Heart J 1992; 13: 1155-1163.

41. Roeters Van Lenner JE, Westerveld HT, et al. Risk factors for coronary heart disease: Implications of gender. Cardiovascular research 2002; 53(3): 538-549.

42. Okonofua EE, Lawal A, Bamgbose JK. Features of Menopause and Menopausal age in Nigerian women. Int J Gynaecol obstet 1990; 31(4): 341-345.

43. Osakue DI. Serum lipid profile of postmenopausal Women in Sapele, Delta state, Nigeria.Journal of Medical Research 2013; 1(1): 9-13.

44. Stensvold I, Iverdal A, Urdal P et al. Non fasting serum triglyceride concentration and mortality from coronary heart disease and any cause in middle aged Norwegian women. $\mathrm{Br}$ Med J 1993; 307: 1318-1322.

45. Drexel H, Aman FH, Rentschk K et al. Relation of the level of high density lipoprotein subfraction to the presence and extent of coronary artery disease. Am J Cardiol 1992; 70: 436-440.

46. Dobiasova M and Frohlich JJ. Structural and functional assessment of high density lipoprotein heterogenicity. Clin chem. 1994; 40: 1554-1558.

47. Dobiavosa M, Urbanova Z, Samanek M. Relation between particle size of HDL and LDL lipoproteins and cholesterol Esterification rate. Physiol Res 2005; 54: 159-165. 